\title{
Detección de vibrio mediante la amplificación de genes de patogenicidad en camarón Litopenaeus vannamei cultivado en un sistema tipo invernadero
}

\author{
Vibrio detection by amplification of pathogenicity genes in shrimp \\ Litopenaeus vannamei cultured in a greenhouse system
}

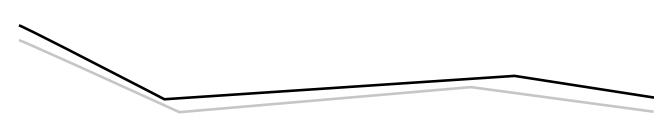

María del Carmen Bermúdez-Almada*®, Angélica Espinosa-Plascencia*, Claudia L. Lara-Espinoza*, Marisela Rivera-Domínguez**, Karen R. Astorga-Cienfuegos**, Enrique Villalpando-Canchola***

\begin{abstract}
Bermúdez-Almada, M. C., Espinosa-Plascencia, A., Lara-Espinoza, C. L., RiveraDomínguez, M., Astorga-Cienfuegos, K. R., \& Villalpando-Canchola, E. (2017). Detección de vibrio mediante la amplificación de genes de patogenicidad en camarón Litopenaeus vannamei cultivado en un sistema tipo invernadero. Investigación y Ciencia de la Universidad Autónoma de Aguascalientes, 25(72), 20-29.
\end{abstract}

RESUMEN

Las infecciones por vibrio son un problema importante en el cultivo de camarón por la alta mortalidad y grandes pérdidas económicas provocadas. El objetivo del estudio fue identificar genes de patogenicidad en bacterias vibrio aisladas de camarón L. vannamei cultivado en un sistema intensivo tipo invernadero con nulo recambio de agua. Se determinó cuenta total bacteriana y de vibrio en hemolinfa, hepatopáncreas y branquias de camarón, de donde se obtuvieron aislados bacterianos para la identificación por PCR de Vibrio ssp., V. harveyi gen de hemolisina (vhh), V. harveyi toxR y otras especies patógenas de vibrio. Se identificaron ambos genes (hemolisina y toxR) en cuatro de los aislados de camarón. Esta metodología puede ser una herramienta en la detección de $\mathrm{V}$.

Palabras clave: Vibrio spp.; Vibrio harveyi; gen toxR; gen hemolisina; Litopenaeus vannamei.

Keywords: Vibrio spp.; Vibrio harveyi; toxR gene; hemolysin gene; Litopenaeus vannamei.

Recibido: 6 de abril de 2017, aceptado: 18 de agosto de 2017

* Laboratorio de Análisis Biológicos, Coordinación de Ciencia de los Alimentos, Centro de Investigación en Alimentación y Desarrollo, A. C. Carretera a la Victoria km 0.6, C. P. 83000, Hermosillo, Sonora, México. Correo electrónico: cbermudez@ciad.mx; angelica@ciad.mx; claudial_ lara@hotmail.com

** Laboratorio de Biotecnología Molecular de Plantas, Coordinación de Ciencia de los Alimentos, Centro de Investigación en Alimentación y Desarrollo, A. C. Carretera a la Victoria km 0.6, C. P. 83000, Hermosillo, Sonora, México. Correo electrónico: marisela@ciad.mx; kastorga@ ciad.mx

*** Laboratorio de Biotecnología Marina, Coordinación de Tecnología de Alimentos de Origen Animal, Centro de Investigación en Alimentación y Desarrollo, A. C. Carretera a la Victoria km 0.6, C. P. 83000, Hermosillo, Sonora, México. Correo electrónico: evillal@ciad.mx

$凶$ Autor para correspondencia harveyi para su prevención y control. No se detectó $V$. cholerae (V. chol), V. vulnificus (Vvh-785) y V. harveyi (LUXN), aspecto importante desde el punto de vista de salud del consumidor.

ABSTRACT

The infections by vibrio are an important problem in shrimp culture due to high mortalities and large economic losses caused. The aim of the study was to identify genes of pathogenicity in vibrio bacteria isolated of $L$. vannamei shrimp cultured in an intensive system on greenhouse with zero water exchange. It was determined total bacterial count and vibrio in hemolymph, hepatopancreas and gills of the shrimp. The strains were identified as Vibrio ssp., $V$. harveyi hemolysin gene (vhh), $V$. harveyi toxR and other pathogenic vibrio species by PCR. Both genes (hemolysin and toxR) were identified in four isolates of shrimp. This methodology could be a tool in the detection of $V$. harveyi for prevention and control. A highlight of this study was the absence of $V$. cholerae (V. chol), V. vulnificus (VVh-785) y V. harveyi (LuXN), an important matter to the consumer health.

\section{INTRODUCCIÓN}

El camarón es uno de los alimentos más populares dentro de los productos acuícolas, y Litopenaeus vannamei es una de las especies de mayor importancia comercial en Asia y América Latina. La producción mundial de camarón de cultivo ascendió a más de 3,000,000 t en el año 2014 (Organización de las Naciones Unidas para la Alimentación y la Agricultura [FAO], 2014). 
Uno de los principales problemas que afecta el desarrollo de la acuicultura es la presencia de enfermedades en los organismos. Las infecciones y la falta de un buen manejo sanitario ocasionan pérdidas económicas millonarias (Zorriehzahra \& Banaederakhshan, 2015).

En el noroeste de México las enfermedades ocasionadas por bacterias del género Vibrio han afectado seriamente la industria acuícola, lo cual ha disminuido considerablemente la producción y generado el cierre de un número considerable de granjas camaronícolas (Bermúdez-Almada, Espinosa-Plascencia, Santiago-Hernández, Barajas-Borgo, \& Acedo-Félix, 2014). Entre las enfermedades más frecuentes que afectan al camarón se encuentran la vibriosis sistémica, la erosión bacteriana del caparazón, el síndrome de Zoea II, la hepatopancreatitis necrotizante (NHP), las infecciones por bacterias filamentosas (Leucothrix mucor) (Leyton \& Riquelme, 2008), y más recientemente, el síndrome de la necrosis hepatopancreática aguda (AHPNS) denominada EMS o síndrome de la mortalidad temprana. Esta última ha perjudicado fuertemente al sector camaronícola del estado de Sonora, se ha identificado como agente causal a Vibrio parahaemolyticus, que afecta a L. vannamei y a Penaeus monodon, a los cuales les produce lesiones histopatológicas en las primeras etapas de desarrollo del camarón (ZOrriehzahra \& Banaederakhshan, 2015).

La severidad de las infecciones depende de la especie de Vibrio involucrada, la etapa de desarrollo del camarón y las condiciones ambientales (Jayasree, Janakiram, \& Madhavi, 2006). Cepas de Vibrio harveyi portadoras del gen hemolisina infectan larvas y camarones en desarrollo, y les causan daño en el hepatopáncreas. El gen de hemolisina en Vibrio harveyi está relacionado con su virulencia y patogenicidad (Parvathi, George, \& Kumar, 2009; Paydar, Shuan, \& Lin, 2013). El factor de virulencia influye en la habilidad de formar biopelículas y secretar proteasas, hemolisinas o lipopolisacáridos que son tóxicos para el camarón (Soonthornchai et al., 2010).

Desde el punto de vista de salud humana y su relación con los organismos acuáticos es importante estudiar la presencia de este patógeno, ya que infecciones causadas por este género se asocian a la ingesta de productos marinos contaminados o al contacto de heridas con agua de mar, en donde el paciente manifiesta gastroenteritis, infecciones en la piel, septicemia y la muerte en pacientes inmunocomprometidos o con bajas defensas (Kumar et al., 2014).

Debido a la difícil situación que representa mantener un control sobre las enfermedades ocasionadas por Vibrio en los cultivos de camarón, se plantea el uso de sistemas de producción cerrados con nulo recambio de agua como una alternativa viable para el cultivo de camarón L. vannamei. Estos sistemas se desarrollan generalmente en áreas pequeñas que permiten mantener un mayor control de las condiciones fisicoquímicas en el cultivo y optimizar la alimentación. Dentro de las ventajas de este sistema está la disminución de eutroficación en los esteros e interacción o transmisión de enfermedades entre las poblaciones silvestres y las cautivas (Ray, Lewis, Browdy, \& Leffler, 2010).

Por otro lado, es importante realizar diagnósticos e identificación de especies bacterianas que presenten genes de patogenicidad como herramientas de prevención y monitoreo para evitar mortalidades masivas de los organismos con las consecuentes pérdidas económicas. En este estudio se planteó identificar genes de patogenicidad en bacterias de Vibrio aisladas de camarón L. vannamei mantenido en un sistema de cultivo intensivo tipo invernadero.

MATERIALES Y MÉTODOS

\section{Diseño experimental}

La investigación se diseñó como estudio de campo descriptivo, durante 59 días en una granja de producción intensiva de camarón L. vannamei, localizada en Bahía de Kino, Sonora, México

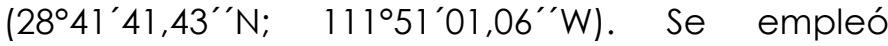
un estanque tipo invernadero de $50 \times 8 \times 1.2 \mathrm{~m}$ (largo, ancho, profundidad), con paredes y fondo cubiertos de plástico liner, mantenido con aireación constante (figura 1) y una densidad de siembra de 126 organismos juveniles $/ \mathrm{m}^{2}$, con un peso inicial de $13.64 \pm 2.0 \mathrm{~g}$. Los organismos se aclimataron durante una semana administrándoles alimento balanceado para camarón (35\% proteína) cinco veces al día, a $3 \%$ de la biomasa.

\section{Parámetros fisicoquímicos}

Se llevó a cabo la medición de parámetros fisicoquímicos durante el bioensayo. El registro de temperatura, oxígeno disuelto (OD) y pH se realizó dos veces al día (06:00 y 17:00 h), empleando un 
IIVESTIGACIÓn Y CIERCIA DE LA UחIVERSIDAD AUTÓNOMTH DE RGUASCALIERTES

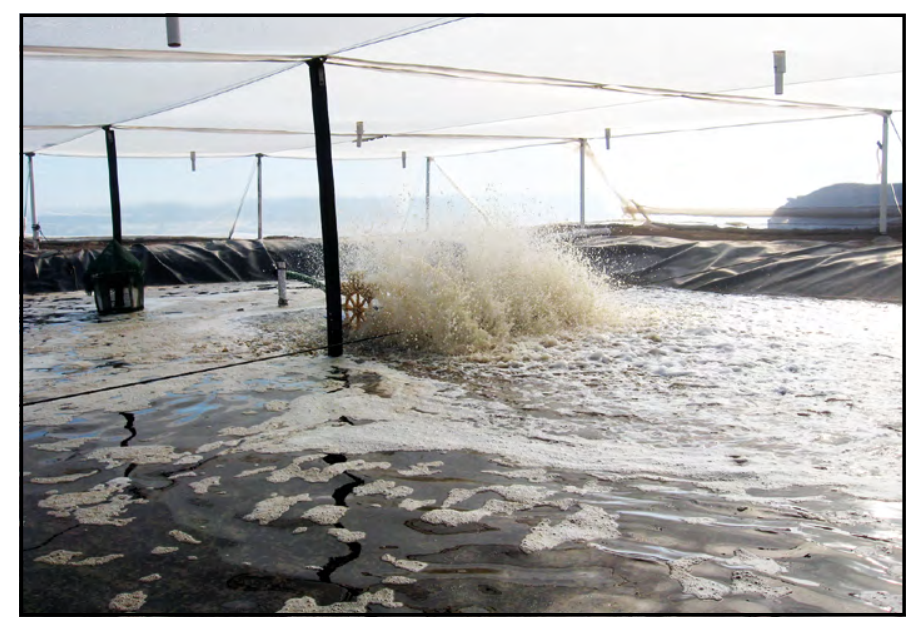

Figura 1. Estanque tipo invernadero con aireación constante. Fotografía de los autores.

oxímetro YSI (YSI 55, Yellow Springs, OH, EE. UU.) y un potenciómetro YSI (Ecosense pH10, Yellow Springs, $\mathrm{OH}, \mathrm{EE}$. UU.). La medición de la salinidad se realizó dos veces por semana empleando un refractómetro Aquatic Eco-Systems (VitalSine SR-6, Apopka, FL, EE. UU.).

Se midió la concentración de nitritos $\left(\mathrm{NO}_{2}\right)$ y nitrógeno amoniacal total (NAT) mediante un fotómetro YSI Ecosense 9500 a una longitud de onda de 520 a $640 \mathrm{~nm}$ y kits comerciales Nitricol (Water Test Tablets Palintest AP 109), amonio No. 1 y No. 2 (Water Test Tablets, Palintest AP 152), siguiendo los procedimientos indicados por el fabricante (AILAPHOTR).

\section{Parámetros biológicos}

La sobrevivencia de los organismos fue establecida mediante la proporción de organismos cosechados al final del experimento con respecto a la cantidad sembrada al inicio, siguiendo el procedimiento establecido por Li et al. (2007):

\section{Sobrevivencia $(\%)=100 \times$ (número final de organismos)/(número inicial de organismos)}

La ganancia de peso se obtuvo aplicando la fórmula propuesta por Pan, Zhang y Liu (2007):

\section{Ganancia de peso $=($ Peso final - Peso inicial $)$ /Tiempo experimental (Número de organismos)}

El factor de conversión alimenticia se calculó empleando la fórmula propuesta por Arnold, Coman, Jackson y Groves (2009):

\section{FCA $=$ Alimento total administrado/Ganancia total de biomasa}

\section{Extracción de hemolinfa, hepatopáncreas y \\ branquias de $L$. vannamei para recuento y aislamiento bacteriano}

$\mathrm{Se}$ tomaron diariamente cinco camarones del estanque, se les extrajo asépticamente la hemolinfa (100 $\mu l)$ colocando el camarón en posición ventrodorsal (boca arriba), dejando expuesta la zona de unión entre el cefalotórax y el abdomen (seno hemolinfático ventral), se empleó una jeringa insulínica de $1 \mathrm{ml}$ conteniendo $100 \mu \mathrm{l}$ del anticoagulante citrato de sodio a $10 \%$ (J.T. Baker, EE. UU.). El procedimiento de extracción se ilustra en la figura 2.

Se adicionaron $50 \mu \mathrm{l}$ de hemolinfa en placas estériles con agar marino (AM) y $50 \mu \mathrm{l}$ en agar tiosulfato citrato bilis sucrosa (TCBS) (Difco, Diagnostic Systems, EE. UU.) homogeneizándolas con extensores Drigalsky estériles. Se registró el volumen de hemolinfa extraído

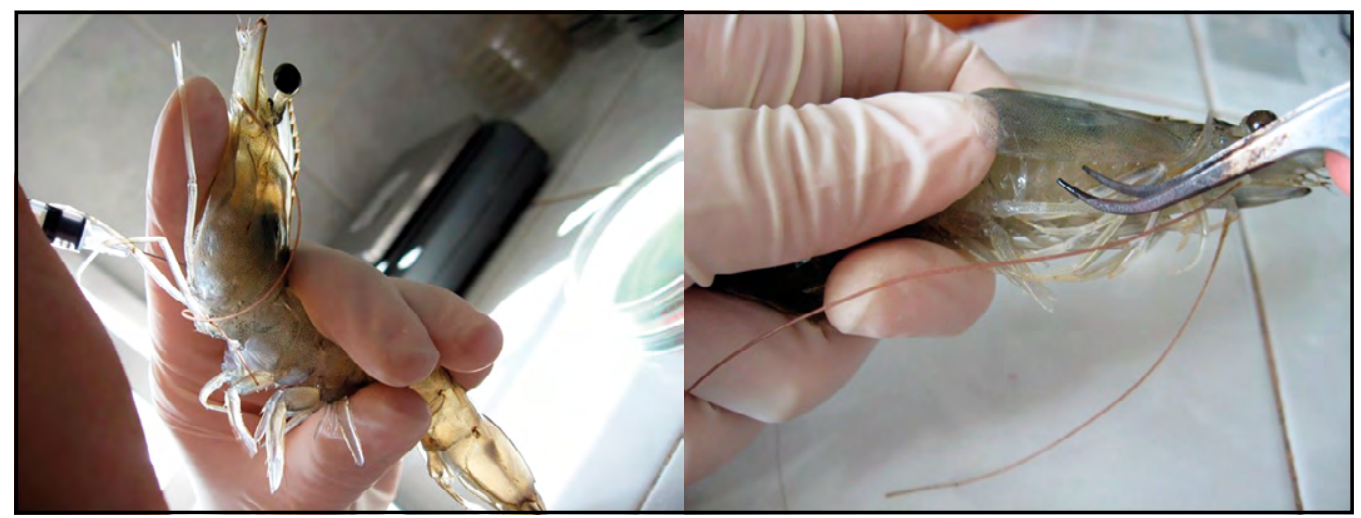

Figura 2. Extracción de hemolinfa y branquias en camarón L. vannamei. Fotografías de los autores. 
para ser considerado en los cálculos finales, UFC/ml= número de colonias/volumen de hemolinfa.

El hepatopáncreas (Hp) y las branquias de los organismos se extrajeron asépticamente (figura 2), registrando el peso de ambos órganos, mismos que se diluyeron por separado en $9 \mathrm{ml}$ de agua peptonada alcalina (APW) con 3.5\% de NaCl (Difco, Diagnostic Systems, EE. UU.). En todas las muestras se realizaron diluciones $1 \times 10^{1}$ hasta $1 \times 10^{4}$, inoculando $100 \mu \mathrm{l}$ de los homogeneizados en placas de AM y $100 \mu \mathrm{l}$ en TCBS adicionado con $2.5 \%$ de $\mathrm{NaCl}$. Se incubaron a $37^{\circ} \mathrm{C} / 24$ h (VWR Scientific Products, mod. 1545, EE. UU.). Para determinar las cuentas bacterianas se consideraron las placas que presentaron un crecimiento entre $25-250$ UFC/ml.

De las placas de agar TCBS se aislaron 208 colonias (104 de hepatopáncreas, 52 de branquias y 52 de hemolinfa) con morfología característica de vibrio (colonias de tamaño mediano de coloración amarilla, lisas, opacas o verdes con halo azul verdoso transparente). A estas se les realizaron las pruebas de diferenciación de especies de vibrio mediante el perfil de pruebas bioquímicas y se seleccionaron 64 aislados; 40 de hepatopáncreas, 16 de branquias y 8 de hemolinfa, los cuales se sembraron en agar soya tripticasa (AST) (BD Bioxon, Becton Dickinson de México) con $3,5 \%$ de $\mathrm{NaCl}$. Se incubaron a $37^{\circ} \mathrm{C} / 24$ h para su posterior identificación por la reacción en cadena de la polimerasa (PCR).

\section{Extracción de ADN de los aislados bacterianos}

La extracción de ADN se estandarizó previamente utilizando cepas de vibrio CAIM (colección de microorganismos de importancia acuática), $V$. parahaemolyticus CAIM 320, V. cholerae CAIM 1409, V. vulnificus CAIM 612 y V. mimicus CAIM 602, donadas por el Centro de Investigación en Alimentación y Desarrollo, A.C., Unidad Guaymas, Sonora, México.

En la extracción de ADN se utilizó el kit comercial para purificación Wizard® Genomic ADN (Promega Inc. Madison, WI, EE. UU.). Se tomaron inóculos de las cepas aisladas en AST y se sembraron en APW con $2 \%$ de $\mathrm{NaCl}$ como preenriquecimiento, $1 \mathrm{ml}$ de este se concentró mediante centrifugación a 15000 × g/2 min (Allegra 64R, Beckman Coulter, EE. UU.) para precipitar las células. Se removió el sobrenadante y se agregaron $600 \mu \mathrm{l}$ de una solución de 1X Tris-búfer EDTA, los tubos se incubaron en un baño de agua (Precision Scientific, mod. 181, Chicago, IL, EE. UU.) a $80^{\circ} \mathrm{C} / 5$ min provocando lisis en las células.
Se enfriaron los tubos a temperatura ambiente y se les adicionó $3 \mu$ de solución de RNasa, mezclando perfectamente. Se incubaron en baño de agua a 37 ${ }^{\circ} \mathrm{C} / 15 \mathrm{~min}$ y se dejaron enfriar. Se les adicionó $200 \mu \mathrm{l}$ de solución para precipitar proteínas, se agitaron en un vórtex a alta velocidad por 20 s, homogeneizando la solución de precipitación de proteínas y las células lisadas.

Se dejaron reposar los tubos en hielo por 5 min y se centrifugaron a $15000 \times \mathrm{g} / 3 \mathrm{~min}$, el sobrenadante con el ADN se transfirió a tubos con $600 \mu \mathrm{l}$ de isopropanol (Fluka, EE. UU.), mezclándolos y centrifugando los tubos a 15000 × g/2 min. Se removió el sobrenadante, los tubos se secaron, se adicionaron $600 \mu \mathrm{l}$ de etanol a $70 \%$ para lavar el precipitado de ADN y se centrifugaron a $15000 \times \mathrm{g} / 2 \mathrm{~min}$. Los tubos se dejaron secar de 10 a 15 min y se agregaron $100 \mu \mathrm{l}$ de la solución 1X Tris-búfer EDTA para resuspender el ADN, se incubaron a $65^{\circ} \mathrm{C} / 1$ h en un baño de agua, agitándolos constantemente. Las muestras de ADN se almacenaron en refrigeración $\left(2-4^{\circ} \mathrm{C}\right)$.

La concentración de ADN se determinó en un espectrofotómetro mod. ND-1000 (NanoDrop Tech. Wilmington, DE, EE. UU.), a una absorbancia de 260 $\mathrm{nm}$.

\section{Identificación de especies de Vibrio por la reacción} en cadena de la polimerasa (PCR)

El análisis de PCR se realizó en los 64 aislados de los tejidos de camarón. Una vez identificadas las cepas de Vibrio spp. se procedió a hacer la amplificación en estas con los oligonucleótidos iniciadores específicos para V. cholerae (V. chol), V. vulnificus (Vvh-785), V. harveyi (LuXN), $V$. harveyi gen de hemolisina (vhh) y $V$. harveyi (toxR) (Sigma-Aldrich). Se utilizó el kit comercial GoTaq® PCR Core Systems (Promega Inc. Madison, WI, EE. UU.) Utilizando una concentración de $100 \mathrm{ng}$ de ADN para todas las muestras en un volumen final de $25 \mu$ l.

La mezcla de reacción consistió en: $1 \mu$ de dNTP's $10 \mathrm{mM}$ (dATP, dGTP, dTTP, dCTP), $2 \mu \mathrm{l}$ de $\mathrm{MgCl}_{2} 25 \mathrm{mM}$, $5 \mu \mathrm{l}$ de $5 x$ búfer GoTaq ${ }^{\circledR}$ con colorante verde, $0,25 \mu l$ de ADN polimerasa GoTaq ${ }^{\circledR}$ y de 0,9 a $1,5 \mu$ de cada oligonucleótido a una concentración de 50 pmol. La amplificación del ADN se hizo en un termociclador Perkin Elmer (DNA Thermal Cycler 480, Norwalk, CT, EE. UU.). Las condiciones de amplificación por PCR para las especies de Vibrio se muestran en la tabla 1 y la secuencia de los oligonucleótidos iniciadores se presenta en la tabla 2. 
Los productos de PCR fueron visualizados en geles de agarosa a 2\% (Sigma-Aldrich, St. Lovis, MO, EE. UU.). Se utilizó una fuente de poder FOTO/Force 250. Las condiciones de electroforesis fueron $85 \mathrm{~V}$ durante $55 \mathrm{~min}$, el colorante utilizado fue bromuro de etidio a una concentración de $24 \mu \mathrm{g} \mathrm{ml}^{-1}$. Se aplicó en los geles una concentración de ADN de 100 ng $\mathrm{\mu l}^{-1}$. El marcador molecular fue ADN Ladder (BIO-RAD, No 170-8200), las bandas en los geles se observaron y fotografiaron en un fotodocumentador (Gel doc $\AA$ $X R+B I O-R A D$, EE. UU.).

Tabla 1

Condiciones de PCR utilizadas en la identificación de especies de bacterias del género Vibrio

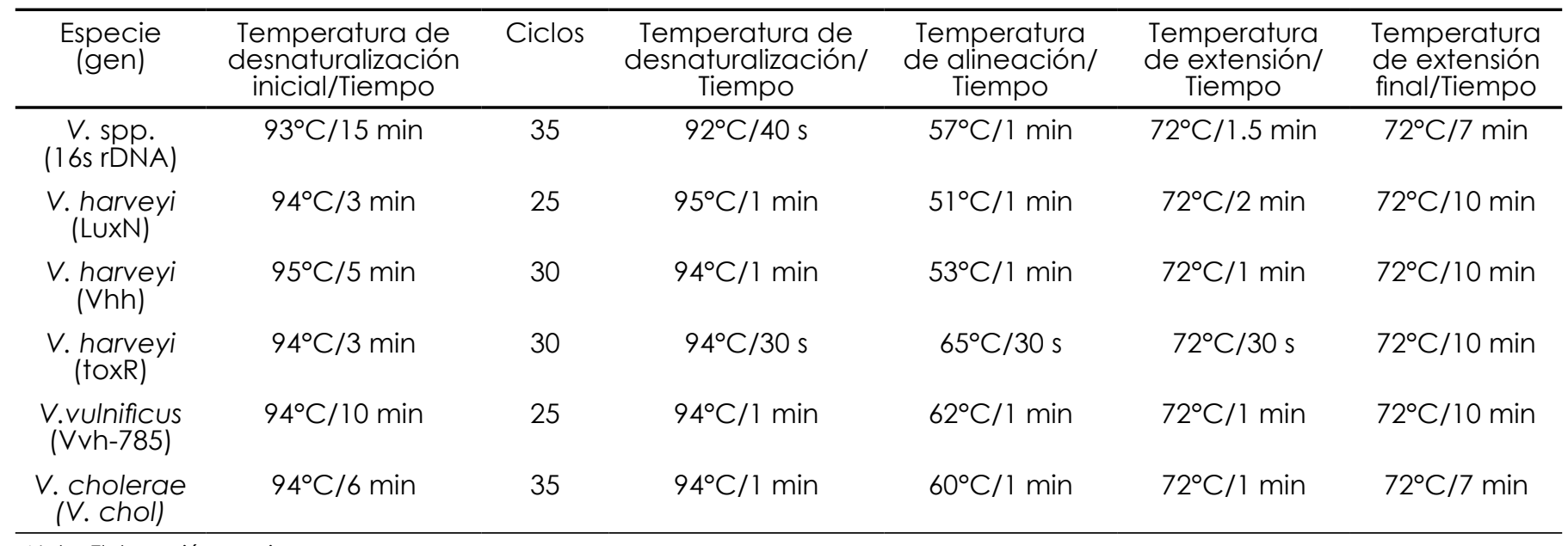

Nota: Elaboración propia.

Tabla 2

Oligonucleótidos iniciadores utilizados en la identificación de especies del género Vibrio

\begin{tabular}{|c|c|c|}
\hline $\begin{array}{l}\text { Especie } \\
\text { (gen) }\end{array}$ & Oligonucleótido iniciador & $\begin{array}{l}\text { Amplicón } \\
\text { (pb) }\end{array}$ \\
\hline $\begin{array}{l}\text { V. spp. } \\
\text { (16s rDNA) }\end{array}$ & $\begin{array}{l}\text { F- 5'-CGGTGAAATGCGTAGAGAT-3' } \\
\text { R-5'-TTACTAGCGATTCCGAGTTC-3' }\end{array}$ & 663 \\
\hline $\begin{array}{l}\text { V. harveyi } \\
\text { (LuXN) }\end{array}$ & $\begin{array}{l}\text { F- 5'CTGTGTACTCACTGTTTATC-3' } \\
\text { R- 5'TCTATCTCTGTAGCCCCTATTACG-3' }\end{array}$ & 2048 \\
\hline $\begin{array}{l}\text { V. harveyi } \\
\text { (vhh) }\end{array}$ & $\begin{array}{l}\text { F-5'-ATCATGAATAAAACTATTACGTTACT-3' } \\
\text { R- 5'-GCTTGATAACACTTTGCGGT-3' }\end{array}$ & 308 \\
\hline $\begin{array}{l}\text { V. harveyi } \\
\text { (toxR) }\end{array}$ & $\begin{array}{l}\text { F- 5'-TTCTGAAGCAGCACTCAC-3', } \\
\text { R- 5'-TCGACTGGTGAAGACTCA-3' }\end{array}$ & 390 \\
\hline $\begin{array}{l}\text { V.vulnificus } \\
\text { (Vvh-785) }\end{array}$ & $\begin{array}{l}\text { F- 5'-CCGCGGTACAGGTTGGCGCA-3' } \\
\text { R- 5'-CGCCACCCACTTTCGGGCC-3' }\end{array}$ & 519 \\
\hline $\begin{array}{l}\text { V. cholerae } \\
\text { (V. chol) }\end{array}$ & $\begin{array}{l}\text { F- 5'-CTCAGACGGGATTTGTTAGGCACG-3' } \\
\text { R- 5'- TCTATCTCTGTAGCCCCTATTACG-3' }\end{array}$ & 302 \\
\hline
\end{tabular}

Nota: Elaboración propia.

RESULTADOS

\section{Parámetros fisicoquímicos}

Los valores obtenidos en los parámetros fisicoquímicos en el agua del estanque de cultivo fueron: temperatura $30.44 \pm 2.09^{\circ} \mathrm{C}$, OD $4.71 \pm 0.64 \mathrm{mg} \mathrm{l}^{-1}$ y pH 7.34 \pm 0.15 . La salinidad registrada fue de $39.9 \pm 0.88 \%$ 。
El nivel promedio de nitritos durante el estudio fue de $4.75 \pm 4.4 \mathrm{mg} \mathrm{l}^{-1}$. Las concentraciones estuvieron en el intervalo de 0.1 a $13.6 \mathrm{mg} \mathrm{H}^{-1}$. La concentración de NAT en el agua del estanque fue de $0.55 \pm 0.27 \mathrm{mg} \mathrm{l}^{-1}$. El valor más alto se registró a los 14 días de iniciado el estudio y fue de $2.88 \mathrm{mg} \mathrm{l-1}^{-1}$; el más bajo fue de $0.10 \mathrm{mg}^{-1}$. 


\section{IIVESTIGAGIÓn Y CUERCIA DE LA UחIVERSIDAD AUTÓNOMA DE AGUASCALIERTES}

\section{Parámetros biológicos}

La sobrevivencia de los organismos mantenidos en el sistema de cultivo cerrado fue de $56.87 \%$, con una biomasa total de $790 \mathrm{~kg}$ en un área de cultivo de 0.04 ha. El incremento promedio en peso de los organismos fue de $1.55 \pm 0.91 \mathrm{~g} / \mathrm{semana}$. Al finalizar el estudio los organismos tuvieron un peso de 27.56 $\pm 1,09 \mathrm{~g}$. El Factor de Conversión Alimenticia fue de 1.31

\section{Recuentos bacterianos}

La cuenta total bacteriana (CTB) que se obtuvo en hemolinfa, hepatopáncreas y branquias de camarón se muestra en la tabla 3 y se expresa en intervalos; se observa que las cuentas fueron relativamente bajas en los distintos tejidos, siendo en hemolinfa en donde se detectó la menor cantidad de bacterias; branquias y hepatopáncreas presentaron una mayor CTB.

Tabla 3

Cuenta total bacteriana en camarón L. vannamei

\begin{tabular}{cc}
\hline Tejido & $\begin{array}{c}\text { Intervalos de } \\
\text { concentración }(\mathrm{UFC} / \mathrm{ml}, \mathrm{g})\end{array}$ \\
\hline $\begin{array}{c}\text { Hepatopáncreas } \\
(\mathrm{n}=96)\end{array}$ & $1.1 \times 10^{2}-6.2 \times 10^{4}$ \\
$\begin{array}{c}\text { Branquias } \\
(\mathrm{n}=32) \\
\text { Hemolinfa } \\
(\mathrm{n}=48)\end{array}$ & $2.5 \times 10^{2}-7.6 \times 10^{4}$ \\
\hline
\end{tabular}

Nota: Elaboración propia.

Durante el estudio se observó que las cuentas de bacterias presuntivas de vibrio obtenidas de hemolinfa, hepatopáncreas y branquias presentaron variabilidad, se mantuvieron cuentas bajas y dentro del intervalo aceptable para estos sistemas de cultivo. La tabla 4 muestra los resultados expresados en intervalos de concentración.

La mayoría de las colonias que crecieron en el agar TCBS fueron de color amarillo como resultado de la utilización oxidativa de la glucosa. Entre las características bioquímicas que presentaron las colonias de vibrio están oxidasa (+), lactosa (-), sacarosa (+), lisina descarboxilasa $(+)$, arginina dihidrolasa (-), ornitina descarboxilasa (-), producción de gas (-), crecimiento s/sal (-).

Identificación molecular de especies de vibrio De los 64 aislados bacterianos que se analizaron por PCR, 12 correspondieron a Vibrio spp. (5 de
Tabla 4

Cuentas de bacterias presuntivas de vibrio aisladas de los diferentes tejidos de camarón L. vannamei

\begin{tabular}{cc}
\hline Tejido & $\begin{array}{c}\text { Intervalos de concentración (UFC/ } \\
\mathrm{ml}, \mathrm{g})\end{array}$ \\
\hline $\begin{array}{c}\text { Hepatopáncreas } \\
(\mathrm{n}=96)\end{array}$ & $5.0 \times 10^{1}-5.9 \times 10^{3}$ \\
$\begin{array}{c}\text { Branquias } \\
(\mathrm{n}=32) \\
\text { Hemolinfa } \\
(\mathrm{n}=48)\end{array}$ & $1.0 \times 10^{2}-1.0 \times 10^{5}$ \\
\hline
\end{tabular}

Nota: Elaboración propia.

branquias, 5 de hemolinfa y 2 de hepatopáncreas). El fragmento amplificado de ADN del gen $16 \mathrm{~s}$ presentó 663 pb, correspondiente a Vibrio spp. Los 12 aislados de Vibrio spp. fueron reanalizados por PCR empleando los oligonucleótidos iniciadores específicos de los genes de virulencia de hemolisina y toxR y para otras especies de vibrio. Se obtuvo la amplificación de fragmentos de ADN para Vibrio harveyi gen hemolisina (vhh) en 6 de los aislados de Vibrio spp. (5 de hemolinfa y 1 de branquias). La expresión de Vibrio harveyi toxR se observó en 3 aislados de branquias y en 3 de hemolinfa. De los 12 aislados, 4 presentaron ambos genes de virulencia, correspondieron 3 a hemolinfa y 1 a branquias.

No se obtuvo la amplificación de estos genes en los aislados de hepatopáncreas. Tampoco se logró la amplificación de los genes para las especies de $V$. cholerae (V. chol), V. vulnificus (Vvh-785) y V. harveyi (LUXN), consideradas en este estudio. Las figuras 3 y 4 muestran los geles con las bandas amplificadas de los genes 16s rADN con 663 pb, Vibrio harveyi gen de hemolisina (vhh) con $308 \mathrm{pb}$ y gen toxR con $390 \mathrm{pb}$, de branquias y hemolinfa de camarón.

\section{DISCUSIÓN}

Los parámetros fisicoquímicos se mantuvieron estables y dentro de los valores óptimos para el desarrollo de L. vannamei, excepto la salinidad que estuvo por arriba del intervalo de 5-35\% reportado como adecuado por Arzola, Piña, Nieves y Medina (2013). Li et al. (2008) mencionan que una alta salinidad en el agua no tiene un efecto adverso en el desarrollo del camarón, ya que una de las características de L. vannamei es su capacidad de tolerar amplios intervalos de esta característica (1$50 \%$ ), sin limitar su desarrollo. 


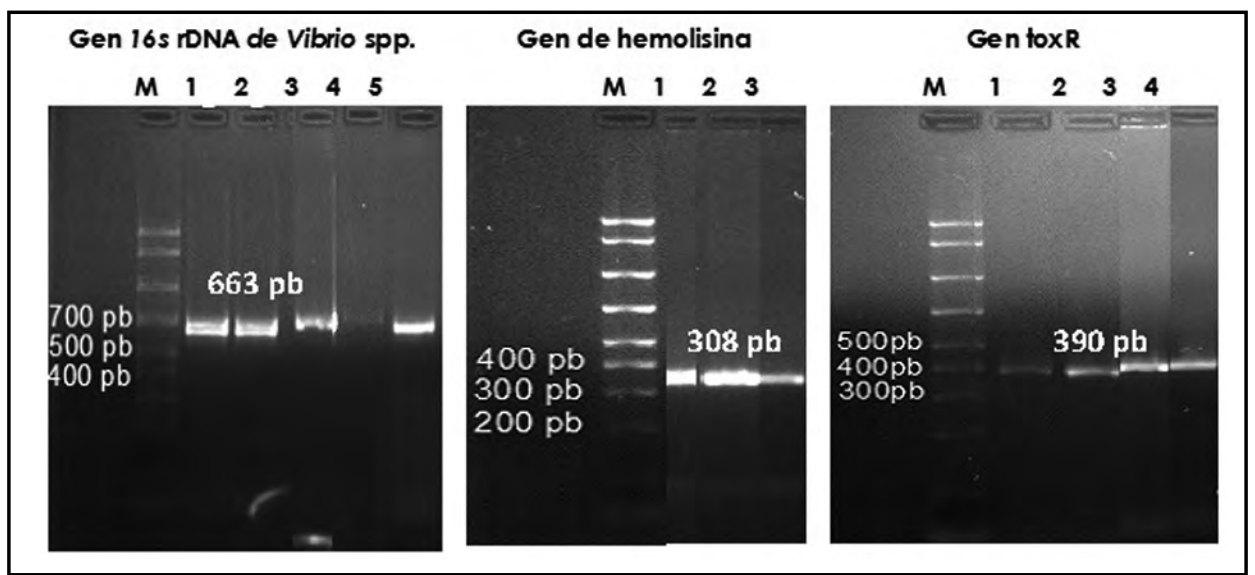

Figura 3. Electroforesis en gel de agarosa de la amplificación del gen 16 rDNA de Vibrio spp. (663 pb), Vibrio harveyi gen de hemolisina (vhh) (308 pb) y Vibrio harveyi gen toxR (390 pb). Carriles 1-5: aislados de branquias de camarón L. vannamei; M: marcador de peso molecular de 50-2000 pb.

Imagen de los autores.

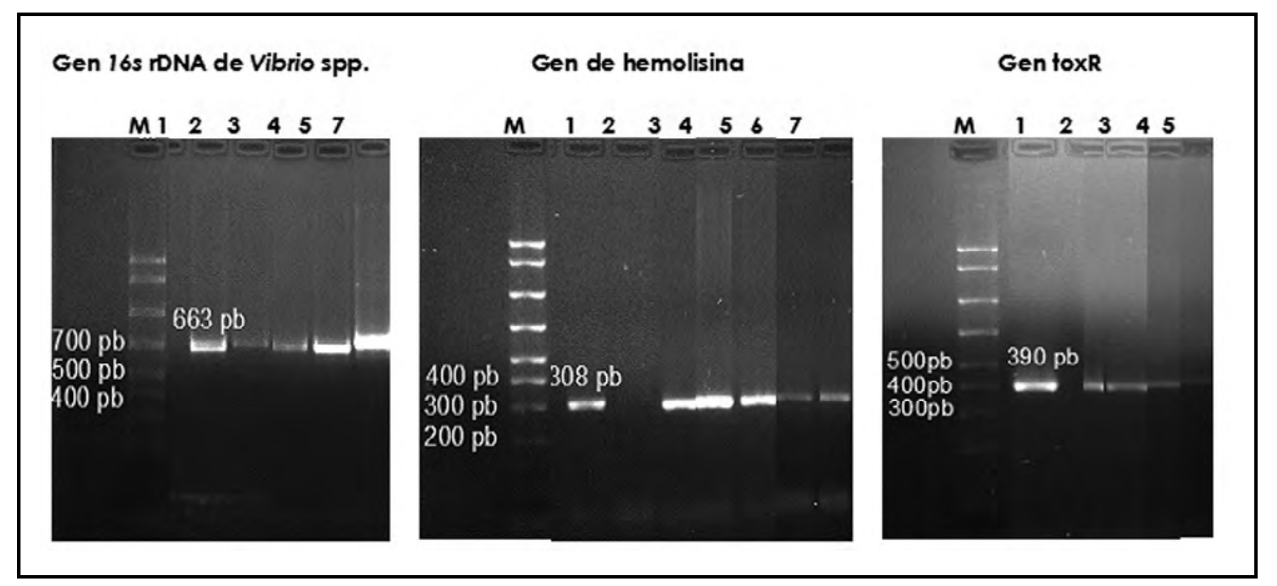

Figura 4. Electroforesis en gel de agarosa para la identificación de Vibrio spp. (663 pb), Vibrio harveyi gen de hemolisina (vhh) (308 pb) y Vibrio harveyi gen toxR (390 pb). Carriles 1-7: aislados de hemolinfa de camarón L. vannamei; M: marcador de peso molecular de 50-2000 pb. Imagen de los autores.

La concentración de nitritos y amonio fue variable, hubo un incremento durante el bioensayo, que pudo deberse a una oxidación incompleta de amonio a nitratos, esto se puede relacionar con una baja presencia de bacterias heterótrofas responsables de la oxidación completa de nitritos a nitratos (Shveitzer et al., 2013). Las variaciones en el NAT estuvieron dentro de los niveles reportados por Zhou, Li, Jun y Bo (2009), que son de $0.1^{-1} .0 \mathrm{mg} \mathrm{l}^{-1}$. Dichas fluctuaciones dependen de la interacción entre las variables temperatura, alcalinidad, salinidad y $\mathrm{pH}$, como lo mencionan Frías-Espericueta y Páez-Osuna (2001).
La sobrevivencia en este estudio fue similar a la obtenida por Lira, Amaral, Moura, Rocha y Correia (2003), quienes reportaron un valor de $56.9 \%$ en sistemas de cultivo semiintensivos. La sobrevivencia puede mejorarse si se mantienen las condiciones fisicoquímicas adecuadas para $L$. vannamei y un control adecuado en la proliferación de Vibrio. La sobrevivencia obtenida puede estar relacionada con las lesiones externas (presencia de necrosis en cutícula, deformaciones de rostro, cambios de coloración de pleópodos) e internas (daño en túbulos del hepatopáncreas, presencia de gregarinas y gametocitos), observadas en los organismos que 
fueron de leves a moderadas en hepatopáncreas (resultados no mostrados).

La ganancia de peso fue similar a la reportada por Cohen, Samocha, Fox, Gandy y Lawrence (2005), quienes obtuvieron incrementos de $1.2 \mathrm{~g}$ por semana en cultivos intensivos con invernadero. Ray, Dillon y Lotz (2011) reportaron que un incremento en peso de 1.1 a $1.5 \mathrm{~g}$ por semana se considera aceptable para camarón L. vannamei en cultivos intensivos. El FCA obtenido se encuentra dentro del intervalo que se reporta como adecuado de acuerdo con Boyd et al. (2001), que es de 1.5 a 2.0; inclusive con las densidades de siembra empleadas en los sistemas intensivos.

Como un indicador del estado de salud de los organismos se determinó la CTB y la identificación de vibrio en el sistema de cultivo evaluado, ya que estas bacterias son causantes de enfermedades con elevadas mortalidades en los estanques de las granjas de cultivo de camarón. La CTB se encontró dentro de los niveles reportados para $L$. vannamei por Gómez-Gil et al. (1998), quienes señalan que conteos menores de $103 \mathrm{UFC} / \mathrm{g}$ o ml en camarón son adecuados en larvas, postlarvas y hemolinfa de juveniles, en sistemas de cultivo sin recambio de agua.

La mayor incidencia de vibrio se obtuvo en las branquias de los organismos, esto por la función de filtración que cumple este órgano, que lo hace mantenerse en contacto directo con el agua del estanque, donde habita vibrio de manera natural (Wu, Chen, \& Huang, 2009). Hossain et al. (2012) reportaron que las cuentas de dicho patógeno en camarón cosechado deben ser entre $1.30 \mathrm{x}$ $10^{3}$ y $1.4^{4} \times 10^{5}$, siendo similar a lo encontrado en este estudio. Diversos factores contribuyen a la expresión de genes de virulencia en las bacterias, algunos se manifiestan en la producción de enzimas como proteasas, lipasas, fosfolipasas, hemolisinas o citotoxinas (Zhang et al., 2014). Por ello, el análisis de fragmentos de secuencias genéticas empleando PCR es una herramienta muy útil que permite caracterizar las distintas especies de vibrio y sus genes de patogenicidad.

El haber detectado el fragmento de ADN que codifica para Vibrio harveyi gen de hemolisina (vhh) fue importante, ya que este gen es considerado un factor de patogenicidad. También está relacionado con la producción de una exotoxina responsable de lisis de eritrocitos y daño en células hospederas (Wong, Zhang, \& Woo, 2012). Por otro lado, la hemolisina es una de la toxinas más ampliamente distribuidas entre las bacterias patógenas del patógeno estudiado y puede ejercer distintos mecanismos durante el desarrollo de la infección (Zhang \& Austin, 2005). Los fragmentos de ADN amplificados que se muestran en los geles de agarosa coinciden con los reportados por Conejero y Hedreyda (2003), quienes utilizaron los mismos oligonucleótidos iniciadores empleados en este estudio, lo que nos indicó que se trata de la misma especie bacteriana.

El gen toxR en Vibrio es considerado un regulador transmembranal de transcripción, que controla la expresión coordinada de los genes de virulencia (Franco \& Hedreyda, 2006). Este gen se emplea como un marcador taxonómico efectivo en la identificación de especies de vibrio (Sani, Ariyawansa, Babji, \& Hashim, 2013). Conejero y Hedreyda (2004) demostraron la utilidad de analizar la secuencia del gen toxR para la diferenciación de vibrio de otras especies filogenéticamente relacionadas. Hossain, Kim y Kong (2013) reportaron evidencias experimentales y epidemiológicas que afirman que la expresión de genes toxR y de hemolisina está relacionada con la patogénesis de la enfermedad.

Desde el punto de vista de salud humana y de su relación con los organismos acuáticos fue importante estudiar la presencia de vibrio con potencial patogénico, ya que infecciones causadas por estos microorganismos se asocian a la ingesta de productos marinos contaminados o al contacto de heridas con agua de mar, en las que el paciente manifiesta gastroenteritis, infección en la piel, septicemia y la muerte en pacientes inmunocomprometidos o con bajas defensas (Kumar et al., 2014). La identificación de cepas de Vibrio harveyi gen de hemolisina (vhh) y gen toxR puede considerarse como un indicador potencial de patogenicidad para el camarón.

CONCLUSIONES

El sistema de cultivo intensivo cerrado permitió mantener los parámetros fisicoquímicos adecuados para el desarrollo de L. vannamei; sin embargo, se detectaron lesiones en los organismos y una reducción en la sobrevivencia que pudiera estar relacionada con la presencia de Vibrio harveyi gen 
de hemolisina (vhh) y gen toxR identificados en hemolinfa y branquias.

Se identificaron aislados de Vibrio harveyi que expresaron ambos genes, hemolisina (vhh) y toxR, principalmente en hemolinfa de camarón. Los hallazgos sugieren que la metodología utilizada podría ser una herramienta en el diagnóstico de estos patógenos en los cultivos de camarón $L$. vannamei.
No se detectaron cepas de $V$. cholerae (V. chol), V. vulnificus (VVh-785) y $V$. harveyi (LuxN) en las muestras de camarón $L$. vannamei, esto fue importante desde el punto de vista de salud para los consumidores.

La utilización de estos sistemas de cultivo intensivo tipo invernadero puede representar una alternativa viable para un mayor control de las enfermedades provocadas por vibrio.

REFERENCIAS

- Arnold, S. J., Coman, F. E., Jackson, C. J., \& Groves, S. A. (2009). High-intensity, zero water-exchange production of juvenile tiger shrimp, Penaeus monodon: An evaluation of artificial substrates and stocking density. Aquaculture, 293(12), 42-48.

- $\quad$ Arzola G., J., Piña V., P., Nieves S., M., \& Medina J., M. (2013). Supervivencia de postlarvas de camarón blanco Litopenaeus vannamei a diferentes salinidades y temperatura. Revista MVZ Córdova, 18(Supl.), 3618-3625.

- Bermúdez-Almada, M. C., Espinosa-Plascencia, A., SantiagoHernández, M. L., Barajas-Borgo, C. J., \& Acedo-Félix, E. (2014). Comportamiento de oxitetraciclina en camarón de cultivo Litopenaeus vannamei y la sensibilidad a tres antibióticos de bacterias de Vibrio aisladas de los organismos. Biotecnia, $16(3), 29-37$

- Boyd, C. E., Treece, G., Engle, R. C., Valderrama, D. V., Lightner, C. R., Pantoja, J., ..., Benner, R. (2001). Consideraciones sobre la calidad del agua y del suelo en cultivos de camarón. En M. C. Haws, \& C. E. Boyd (Ed.), Métodos para mejorar la camaronicultura en Centroamérica (pp. 1-30). Managua, Nicaragua: Editorial-Imprenta UCA.

- Cohen, J. M., Samocha, T. M., Fox, J. M., Gandy, R. L., \& Lawrence, A. L. (2005). Characterization of water quality factors during intensive raceway production of juvenile Litopenaeus vannamei using limited discharge and biosecure management tools. Aquacultural Engineering, 32(3-4), 425442.

- Conejero, M. J., \& Hedreyda, C. T. (2003). Isolation and partial toxR gene of Vibrio harveyi and design of toxR-targeted PCR primer for species detection. Journal of Applied Microbiology, $95(3), 602-611$. (2004). PCR detection of hemolysin (vhh) gene in Vibrio harveyi. Journal of General Applied Microbiology, 50(3), 137-142.
- Franco, P., \& Hedreyda, C. (2006). Amplification and sequence analysis of the full length toxR gen in Vibrio harveyi. The Journal of General Applied Microbiology, 52 (5), 281-287.

- Frías-Espericueta, M. G., \& Páez-Osuna, F. (2001). Toxicidad de los compuestos del nitrógeno en camarones. En F. PaézOsuna (Ed.), Camaronicultura y medio ambiente (pp. 253276). Sinaloa, México: Colegio de Sonora.

- Gómez-Gil, B., Tron-Mayén, L., Roque, A., Turnbull, J. F., Inglis, V., \& Guerra-Flores, A. L. (1998). Species of Vibrio spp. isolated from hepatopancreas, hemolymph and digestive tract of a population of health juvenile Penaeus vannamei. Aquaculture, 163(1-2), 1-9.

- Hossain, M. S., Aktaruzzaman, M., Fakhruddin, A. N. M., \& Uddin, M. J. (2012). Antimicrobial susceptibility of Vibrio species isolated from brackish water shrimp culture environment. Journal of Bangladesh Academic of Science, 36(2), 213-220.

- Hossain, M. T., Kim, Y. O., \& Kong, I. S. (2013). Multiplex PCR for the detection and differentiation of Vibrio parahaemolyticus strains using the groEL, tdh and trh genes. Molecular and Cellular Probes, 27(5-6), 171-175.

- Jayasree, L., Janakiram, P., \& Madhavi, R. (2006). Characterization of Vibrio spp. associated with diseased shrimp from culture ponds of Andhra Pradesh (India). Journal of the World Aquaculture Society, 37(4), 523-532.

- Kumar, B. K., Deekshit, V. K., Raj, J. R. M., Rai, P., Shivanagowda, B. M., Karunasagar, I., \& Karunasagar, I. (2014). Diversity of Vibrio parahaemolyticus associated with disease outbreak among cultured Litopenaeus vannamei (Pacific white shrimp) in India. Aquaculture, 433, 247-251.

- Leyton, Y., \& Riquelme, C. (2008). Vibrio en los sistemas marinos costeros. Revista de Biología Marina y Oceanografía, 43(3), 441-456. 


\section{IIVESTIGAGIÓn Y CUERCIA DE LA UחIVERSIDAD AUTÓNOMA DE AGUASCALIERTES}

- Li, E., Chen, L., Zeng, C., Chen, X., Yu, N., Lai, Q., \& Qin, J. G. (2007). Growth, body composition, respiration and ambient ammonia nitrogen tolerance of juvenile white shrimp, Litopenaeus vannamei, at different salinities. Aquaculture, 265(1-4), 385-390.

- Li, E., Chen, L., Zeng, C., Yu, N., Xiong, Z., Chen, X., \& Qin, J. G. (2008). Comparison of digestive and antioxidant enzymes activities, haemolymph oxyhemocianin contents and hepatopancreas histology of white shrimp, Litopenaeus vannamei, at various salinities. Aquaculture, 274, 80-86.

- Lira, J. R., Amaral, R., Moura, V. F., Rocha, L., \& Correia, E. S. (mayo, 2003). Performance evaluation of Litopenaeus vannamei marine shrimp in intensive and semi-intensive farming systems. World Aquaculture Society 2003. Salvador, Bahia, Brazil, May 19-23, 423-424.

- Organización de las Naciones Unidas para la Alimentación y la Agricultura. (2014). El estado mundial de la pesca y la acuicultura: Oportunidades y desafíos (pp. 20-25). Roma, Italia: Autor.

- Pan, L., Zhang, L., \& Liu, H. Y. (2007). Effects of salinity and $\mathrm{pH}$ on ion-transport enzyme activities, survival and growth of Litopenaeus vannamei postlarvae. Aquaculture, 273(4), 711720.

- Parvathi, A., George, J., \& Kumar, S. (2009). Prevalence and heterogeneity of haemolysin gene vhh among hatchery isolates of Vibrio harveyi in India. Current Microbiology, 59(1), 42-47.

- Paydar, M., Shuan, J. T. C., \& Lin, T. K. (2013). Prevalence and characterisation of potentially virulent Vibrio parahaemolyticus in seafood in Malaysia using conventional methods, PCR and REP-PCR. Food Control, 32(1), 13-18.

- Ray, A. J., Dillon, K. S., \& Lotz, J. M. (2011). Water quality dynamics and shrimp (Litopenaeus vannamei) production in intensive, mesohaline culture systems with two levels of biofloc management. Aquacultural Engineering, 45(3), 127-136.

- Ray, A. J., Lewis, B. L., Browdy, C. L., \& Leffler, J. W. (2010). Suspended solids removal to improve shrimp (Litopenaeus vannamei) production and an evaluation of a plant-based feed in minimal-exchange, superintensive culture systems. Aquaculture, 299(1-4), 89-98.
- Sani, N. A., Ariyawansa, S., Babji, A. S., \& Hashim, J. K. (2013). The risk assessment of Vibrio parahaemolyticus in cooked black tiger shrimps (Penaeus monodon) in Malaysia. Food Control, 31 (2), 546-552.

- Shveitzer, R., Arantes, R., Costódio, P. F. S., do Espíritu Santo, C. M., Arana, L. V., Seiffert, W. Q., \& Adreatta, E. R. (2013). Effect of different biofloc levels on microbial activity, water quality and performance of Litopenaeus vannamei in a tank system operated with no water exchange. Aquacultural Engineering, $56,59-70$.

- Soonthornchai, W., Rungrassamee, W., Karoonuthaisiri, N., Jarayabhand, P., Klinbunga, S., Soderhall, K., \& Jiravanichpaisal, P. (2010). Expression of immune-related genes in the digestive organ of shrimp, Penaeus monodon, after an oral infection by Vibrio harveyi. Developmental \& Comparative Immunology, $34(1), 19-28$.

- Wong, S. K., Zhang, X. H., \& Woo, N. Y. S. (2012). Vibrio alginolyticus thermolabile hemolysin (TLH) induces apoptosis, membrane vesiculation and necrosis in sea bream erythrocytes. Aquaculture, 330-333, 29-36.

- Wu, J. P., Chen, H. C., \& Huang, D. J. (2009). Histopathological alterations in gills of white shrimp, Litopenaeus vannamei (Boone) after acute exposure to cadmium and zinc. Bulletin of Environmental Contamination and Toxicology, 82(1), 90-95.

- Zhang, X. H., \& Austin, B. (2005). Review: Haemolysins in Vibrio species. Journal of Applied Microbiology, 98(5), 1011-1019.

- Zhang, X. J., Yan, B. L., Bai, X. S., Bi, K. R., Gao, H., \& Qin, G. M. (2014). Isolation and characterization of Vibrio parahaemolyticus and Vibrio rotiferianus associated with mass mortality of Chinese shrimp (Fenneropenaeus chinensis). Journal of Shellfish Research, 33(1), 61-68.

- Zhou, Q., Li, K., Jun, X., \& Bo, L. (2009). Role and functions of beneficial microorganisms in sustainable aquaculture. Bioresource Technology, 100(16), 3780-3786.

- Zorriehzahra, M. J., \& Banaederakhshan, R. (2015). Early Mortality Syndrome (EMS) as new emerging threat in shrimp industry. Advances in Animal and Veterinary Sciences, 3(2s), 64-72. 